\title{
La regulación de los campos de golf en la Comunidad Autónoma de Andalucía: ¿interés turístico o interés inmobiliario?
}

\author{
Pedro Górgolas Martín ${ }^{1} \bowtie$ \\ Recibido 08/02/2017 | Aceptado 25/05/2017
}

\section{Resumen}

El objetivo del presente artículo es realizar una disección profunda de la regulación existente en la Comunidad Autónoma de Andalucía para habilitar la implantación de campos de golf. El estudio realizado evidencia la contradicción existente entre la apuesta por fomentar la cualificación de esta oferta deportiva -para lo cual se entiende necesario declarar incompatibles los usos residenciales- y la especial relevancia otorgada a la figura del «campo de golf de interés turístico» que, en realidad, se constituye en una excusa para perpetuar la «asociación siamesa» entre campos de golf y operaciones inmobiliario-residenciales que ha inundado los territorios turísticos de la región andaluza, con especial incidencia en el dominio territorial del litoral.

Palabras clave: campo de golf de interés turístico; usos residenciales; planificación territorial; planeamiento urbanístico; desregulación.

\section{Abstract \\ The regulation of golf courses in the community autonomous of Andalusia: tourist interest or business interest?}

The aim of the article is make a deep dissection of the regulation existing in the autonomous community of Andalusia for the implantation of golf courses. The study shows the contradiction between the bet - declared the Decree 43/2008 - to promote the qualification of this variety of sports - for which means necessary declaring incompatible residential uses - and the special importance given to the figure of the "golf course of tourist interest» which, in reality, constitutes an excuse for perpetuating the siamese association between golf courses and residential operations that it has flooded the tourist of the Andalusian region territories, with special virulence in the territorial domain of the coast.

Key words: golf course of tourist interest ; uses residential; territorial planning ; urban planning; deregulation.

1. Universidad de Sevilla. pedrogorgolas@gmail.com 


\section{Résumé}

\section{Le règlement des champs de golf dans la communauté autonome d'Andalousie: intérêt touristique ou intérêt immobilier ?}

Lobjectif de l'article est de faire une dissection profonde du règlement existant dans la communauté autonome d'Andalousie pour l'implantation de champs de golf. Létude montre la contradiction entre le pari - proclamé le Décret $43 / 2008$ - pour promouvoir la qualification de cette variété de sports - pour quels moyens nécessaires déclarant incompatible résidentiel utilise - et l'importance particulière accordée à la figure du « champ de golf d'intérêt touristique » qui, en réalité, constitue un prétexte pour perpétuer le siamois association entre les champs de golf et opérations immobilier, qu'il a inondé le touriste des territoires région andalouse, avec une virulence particulière dans le domaine des territoires du littoral.

Mots-clés : Champ de golf d'intérêt touristique; les usages résidentiels; l'aménagement du territoire; urbanisme; déréglementation.

\section{Introducción y objetivos}

El fenómeno de los campos de golf ha sido ampliamente estudiado por el campo disciplinar de la Geografía Física (Navarro, 2008; Villar, 2008; Babinger, 2012) direccionándose, fundamentalmente, a diagnosticar las nocivas repercusiones territoriales y ambientales que la implantación de estas instalaciones deportivas ha ocasionado en los territorios turísticos. En el caso concreto de Andalucía, existen brillantes trabajos de investigación (Villar, 2010; Villar y Fernández, 2013; Requejo, 2014) que desvelan el impacto causado por el proceso de urbanización asociado al campo de golf en los destinos turísticos del litoral, tanto maduros -Costa del Sol- como emergentes: Litoral Occidental de Huelva, Bahía de Cádiz o el Levante almeriense. Así, sólo 7 de los 106 campos de golf andaluces están desvinculados de promociones inmobiliarias y, en el año 2006, los complejos inmobiliarios del golf explicaban el $21 \%$ de la trama urbana del litoral andaluz, cifra que se elevaba al 48\% en la Costa del Sol Occidental (Villar, 2010).

Ante las incuestionables patologías causadas por esta casuística, la Comunidad Autónoma Andaluza tomó conciencia, en los estertores de la burbuja inmobiliaria, de la imperiosa necesidad de elaborar una regulación que determinase las condiciones a cumplir para la implantación, diseño y configuración de campos de golf y, ante todo, definiese y explicitase -con la nitidez que demanda la seguridad jurídica a aportar por el marco regulador- el posicionamiento de la Administración Autonómica acerca del problema asociado a la dimensión inmobiliario-residencial que ha caracterizado la implantación de estos equipamientos deportivos en la región andaluza desde mediados los años 90 del siglo XX. Las estudios realizados sobre esta regulación provienen, básicamente, de la disciplina del Derecho (García, 2004; Mellado, 2008; Ortega, 2008; Ortega, 2010; Barranco y Fernández, 2009; Barranco, 2010) y, por tanto, se centran, sustancialmente, en diseccionar el régimen jurídico-normativo aplicable a la implantación de campos de golf y las cuestiones procedimentales que avalan la aprobación administrativa de estas iniciativas.

Estos trabajos no suelen evaluar, con la profundidad que sería preciso, los condicionantes que, para el establecimiento de modelos urbano-territoriales por la planificación territorial y el planeamiento urbanístico, impone este marco legal: ¿Cómo inciden las actuaciones urbanísticas vinculadas a campos de golf en el tipo de ciudad preceptuado en la Ley de Ordenación Urbanística 
de Andalucía (LOUA)? ¿Contribuyen a garantizar la compacidad del sistema de asentamientos -axioma que impregna la normativa sobre modelo de ciudad del Plan de Ordenación del Territorio de Andalucía (POTA)- o, por el contrario, fomentan la configuración de un modelo territorial difuso? ¿Cómo impactan en el cumplimiento de los límites al crecimiento urbanístico regulados en la Norma 45 del POTA? ¿Qué ocurre con la reserva obligatoria de vivienda protegida regulada -en el artículo 10 de la LOUA- como obligatoria para aquellas actuaciones que contemplen usos residenciales?

El presente artículo trata de responder a estas cuestiones y pretende, con ello, contribuir, desde el campo disciplinar de la Urbanística y la Ordenación del Territorio, a enriquecer la reflexión sobre esta materia aportando una visión trasversal de este marco regulatorio -trascendiendo, por tanto, su específica dimensión jurídico-normativa- entablando relaciones con la legislación urbanística y la normativa territorial de ámbito regional vigentes en Andalucía. La finalidad de este estudio es alertar de la sinrazón que caracteriza la secuencia regulatoria seguida en esta materia en esta Comunidad, expresiva de una estrategia de política territorial claramente alineada con las tesis del urbanismo neoliberal que proclaman la liberalización del marco regulatorio para «dejar hacer» al mercado inmobiliario (Roch, 2006; Rodríguez y López, 2010). A tal efecto y como expresión palmaria de esta afirmación, emerge una figura denominada "campos de golf de interés turístico» conceptuada de especial relevancia por su contribución a la dinamización turística pero que, a la postre, representa una válvula de escape para perpetuar la simbiosis entre los campos de golf y la segunda residencia vacacional que ha caracterizado la producción de gran parte de los espacios turísticos de última generación.

\section{Metodología}

Los principales materiales empleados para el desarrollo del presente trabajo han sido los diferentes textos legales que han ido conformado, a lo largo de estos años, el ordenamiento jurídico existente en la Comunidad Andaluza en relación a la temática de los campos de golf: (a) Decreto 43/2008, de 12 de febrero, regulador de las condiciones de implantación y funcionamiento de los campos de golf, (b) Ley 1/2008, de 27 de Noviembre, de medidas tributarias y financieras de impulso a la actividad económica de Andalucía y de agilización de los procedimientos administrativos, que modifica la Ley 1/1994 de Ordenación del Territorio de Andalucía al objeto de regular las «declaraciones de campos de golf de interés turístico», (c) Decreto 309/2010, de 15 de junio, por el que se modifica el Decreto 43/2008 adaptándolo a los nuevos preceptos introducidos por la Ley $1 / 2008$ y (d) Orden $2 / 2012$, de 13 de marzo de 2012 por la que se desarrolla el procedimiento para obtener la declaración de campos de golf de interés turístico.

Dada la orientación disciplinar de este trabajo, el procedimiento seguido para diagnosticar este marco regulatorio ha sido selectivo; es decir, se han discriminado aquellas disposiciones legales que impactan, inciden o, cuanto menos, condicionan el ejercicio de la planificación territorial y urbanística: (a) concepto de campo de golf e instalaciones asociadas; (b) concepto de terrenos adscritos al campo de golf; (c) definición de los usos complementarios, compatibles e incompatibles con los campos de golf; (d) condiciones urbanísticas de la implantación y (e) procedimiento aprobatorio de la declaración de interés turístico y su impacto en la planificación territorial y urbanística.

Complementariamente, para desarrollar la visión trasversal antes apuntada, se ha entendido necesario verificar el impacto de estas disposiciones en aquellas de la legislación urbanística y la 
planificación territorial de ámbito regional que presentan relación directa con esta temática: (a) incidencia en la ordenación del sistema de asentamientos y el tipo de ciudad a establecer por el planeamiento general; (b) cumplimiento de los límites al crecimiento urbano impuestos por el POTA y (c) afección a la reserva obligatoria de vivienda protegida establecida en la LOUA para aquellas actuaciones que desarrollen usos residenciales.

En concreto, las fuentes legislativas y los instrumentos de planificación territorial consultados han sido: (a) Ley 7/2002 de Ordenación Urbanística de Andalucía ( revisión vigente desde el 6 de Agosto de 2016), (b) Decreto 206/2006, de 28 de noviembre, por el que se adapta el Plan de Ordenación del Territorio de Andalucía a las Resoluciones aprobadas por el Parlamento de Andalucía y (c) Ley 2/2012 de 30 de enero de modificación de la Ley 7/2002 de 17 de diciembre de Ordenación Urbanística de Andalucía.

Por último quisiera significar la relevancia que, para la metodología empleada, tiene el conocimiento adquirido por el autor sobre la temática objeto de estudio, destilado de su experiencia en el desarrollo de investigaciones académicas -Tesis Doctoral y Proyecto de Investigación «El Urbanismo de la no ciudad: de la clandestinidad vulnerable a la visibilidad sostenible»- y su implicación en la redacción de instrumentos de planificación territorial y planeamiento general, así como de proyectos de incitativas de implantación de campos de golf para su declaración de interés turístico.

\section{El Decreto 43/2008, de 12 de febrero, regulador de las condiciones de implantación y funcionamiento de campos de golf en Andalucía}

Este Decreto se formula al objeto de regular la definición precisa del concepto de campo de golf estableciendo una distinción rigurosa entre los usos que forman parte de la instalación deportiva, los usos complementarios y compatibles que pueden acompañarla para desarrollar estrategias turísticas de calidad y aquellos que han de ser considerados incompatibles por su negatividad territorial, medioambiental y turística, entre los que se encuentran, como veremos a continuación, los usos residenciales.

Esta decisión impacta en la línea de flotación de la estrategia de ordenación adoptada hasta ese momento en el litoral andaluz, donde los desarrollos urbanísticos que contemplan la presencia conjunta de campos de golf con urbanizaciones turístico-residenciales eran, sin lugar a dudas, el producto estrella (Villar y Fernández, 2013: 364), permanentemente requerido tanto por los municipios -como reclamo para la atracción de un teórico turismo de calidad (Paniza, 2005a y 2005b)- como por el sector promotor al objeto de desarrollar una oferta de segunda vivienda vacacional para la que el simple anuncio de la presencia del campo de golf introducía una importante plusvalía que la hacía irresistible para la demanda inmobiliaria tanto nacional como extranjera. Podemos imaginar la confrontación que, tanto con las corporaciones locales como con propietarios de suelo y promotores, produjo esta firme y decidida declaración de intenciones realizada por la Administración Autonómica por cambiar el rumbo de los criterios que habían orientado, hasta entonces, la ordenación territorial y urbanística de los ámbitos de la región de contrastada potencialidad turística (especialmente el dominio territorial del litoral).

En su Exposición de Motivos, se afirma que el Decreto no sólo responde a la importancia deportiva, turística o económica del fenómeno golf, sino que también atiende a sus dimensiones medioambientales y urbanísticas que se propone encauzar de forma positiva, compatibilizando la promoción del 
golf-como nuevo eje de desarrollo deportivo y turístico-con la preservación del patrimonio natural, la reducción de impactos territoriales o medioambientales $y$, cuando lo posibiliten los ámbitos de implantación, con la mejora y regeneración de los entornos naturales. En conclusión, el Decreto 43/2008 realiza un importante esfuerzo por conciliar las normas y principios de protección ambiental con los de la ordenación territorial y urbanística (Blanquer, 2002 y 2005).

El énfasis en la cualificación turística aparentemente pretendida en esta regulación, presentaba dos rostros: un diseño de altas prestaciones para la instalación deportiva -para lo cual había que impedir la proliferación de las adherencias residenciales que suelen fachadizar su perímetro- y la apuesta por la materialización de alojamientos hoteleros de calidad, como principal argumento de desestacionalización del uso de los espacios turísticos.

Este objetivo cualificador se concreta en la regulación de un régimen general para la implantación de los campos de golf y la de sus usos complementarios y compatibles, orientado a conformar iniciativas que integren instalaciones deportivas de calidad con las actividades dotacionales, de ocio y de alojamiento hotelero necesarias para configurar nuevas centralidades territoriales de excelencia en los destinos turísticos de Andalucía. Además, al objeto de reforzar esta directriz de política territorial, se crea una figura estelar, denominada "campo de golf de interés turístico» otorgándole una vocación estratégica para el impulso de un sector económico trascendental para la región andaluza.

Ante el afloramiento inesperado de esta tipología de campos de golf, la pregunta que cabría hacerse es: ¿En que se fundamenta la singularidad demandada a los campos de golf de interés turístico?, ¿Significa esto que los campos de golf adscritos al régimen general regulado en el Decreto, no inciden en la cualificación de la oferta turística de la Comunidad Andaluza? Como se verá a continuación, más allá de algunas prescripciones técnicas suplementarias destinadas a mejorar el diseño de la instalación deportiva, y el señuelo semántico que comporta la regulación de »acciones para la sostenibilidad» el verdadero hecho diferencial, el principal factor de singularidad, la condición central que justifica el interés turístico de estas iniciativas es la admisibilidad del uso residencial. Sí, no es un error de redacción. El principal de los usos pormenorizados considerados incompatibles con los campos de golf en el propio Decreto -por su contrastada influencia en la descualificación de la instalación deportiva y su «efecto arrastre» hacia la precariedad del propio producto turístico y, por añadidura, del territorio en el que se implanta- es el que ha de caracterizar la especial relevancia de determinadas iniciativas turísticas vinculadas al desarrollo de estos equipamientos deportivos.

El Decreto 43/2008 es un ejemplo paradigmático de la "condición bipolar» que, en materia de ordenación del territorio y planeamiento urbano, ha adoptado la política territorial instrumentada en la Comunidad Andaluza al legislar en un sentido y su contrario. En esta cuestión, además, la constatación de esta bipolaridad no ha precisado de la formulación de otros textos legislativos (Leyes, Decretos-Ley, Decretos u Órdenes), sino que el propio Decreto 43/2008 incluye esta doble condición y desarrolla sus propias contradicciones. Una estrategia que podríamos adjetivar de paradójica, errática y, en cierto modo, incomprensible.

El análisis, que a continuación se muestra, de la regulación establecida en el Decreto 43/2008, se centra en las cuestiones que inciden directamente en la capacidad decisoria de los instrumentos de planificación territorial y urbanística para ordenar el sistema de asentamientos: (a) la concreción del concepto del campo de golf y sus instalaciones asociadas, (b) los usos compatibles y complementarios admisibles, (c) los usos incompatibles, (d) las condiciones urbanísticas regula- 
das para su implantación y, finalmente, (e) el surgimiento sorpresivo de la figura de los campos de golf de interés turístico que, como se ha comentado, contradice todo el entramado regulatorio del Decreto volcado en aportar racionalidad a la ordenación de los territorios donde se implantan estos equipamientos deportivos, al objeto de que recuperen la dimensión turística perdida debido a su asociación mayoritaria con productos inmobiliario-residenciales.

\subsection{La regulación del régimen general de los campos de golf: usos complementarios, compatibles e incompatibles, requisitos territoriales y condiciones urbanísticas para la implantación}

En un primer conjunto de artículos (los que se incluyen entre los Capítulos I a IV), el Decreto desarrolla las disposiciones necesarias para regular correctamente la práctica del golf, vinculando la instalación deportiva con aquellos usos y funciones que contribuyan a conformar productos turísticos de calidad y estableciendo las condiciones urbanísticas a cumplimentar para su correcta implantación territorial.

Entre las disposiciones contenidas en este conjunto de artículos destaca, en primer lugar, la propia definición del concepto de campo de golf (artículo 2), entendiendo por tal la instalación destinada a la práctica de este deporte que cumpla con los requerimientos y especificaciones técnicas exigidas por el organismo competente para regular su práctica y reúna las condiciones de calidad exigidas en el propio Decreto. En este concepto se encuentran incluidas, además de la superficie destinada a campo de juego, las instalaciones necesarias para la práctica deportiva y el acceso de las personas usuarias, tales como instalaciones de mantenimiento y maquinarias, aparcamiento de vehículos para uso de personas usuarias y trabajadoras, almacenaje, caseta de palos, casa club, tienda de golf, restaurante, vestuarios y similares. Los campos de golf que se adecúen a esta definición serán considerados de incidencia territorial e interés supramunicipal explicitando, de esta forma, la significación otorgada a estos equipamientos deportivos.

Por otro lado, el Decreto considera terrenos adscritos al campo de golf (artículo 4) aquellos que, situados en continuidad con el mismo, alberguen un uso complementario o compatible autorizado, así como los necesarios para el mantenimiento y recuperación medioambiental de los terrenos en los que se implanten campos de golf (artículo 10). Los usos complementarios admitidos pueden ser otras instalaciones deportivas, establecimientos hoteleros con una categoría mínima de cuatro estrellas e instalaciones de ocio, esparcimiento y restauración y, los usos compatibles, los destinados a dotaciones y equipamientos de carácter asistencial, sanitario, administrativo o cultural.

Con esta regulación el Decreto 43/2008 incorpora tres disposiciones de gran importancia para impulsar un cambio de ciclo en la ordenación de los espacios turísticos: (a) la diferenciación localizativa entre la instalación deportiva y los terrenos adscritos, (b) la apuesta firme y decidida por el uso hotelero como oferta de alojamiento asociada y (c) la necesidad de reforzar la oferta dotacional con equipamientos de alto valor añadido.

La obligación de localizar los terrenos adscritos «en continuidad con el campo de golf», provoca que el diseño de la instalación deportiva rompa con la inercia habitual y se oriente a crear condiciones óptimas para la práctica deportiva (Villar y Fernández, 2013: 365). Por su parte, la complementariedad en materia de alojamiento -restringida a la implantación de piezas hoteleras de calidad (mínimo de 4 estrellas)- trata de fortalecer la condición turística de la actuación, otorgando protagonismo a esta tipología de alojamiento frente al uso residencial-vacacional. Destaca 
el énfasis selectivo de la regulación establecida ya que, entre las diferentes categorías de establecimientos de alojamiento turístico (hoteleros y apartamentos) reguladas en la legislación andaluza -Decretos 47/2004 y 194/2010- se opta por la que aporta mayor cualificación a la oferta alojativa existente en el destino en el que se va a implantar la iniciativa.

Finalmente, se promueve complementar la instalación deportiva con la implantación de otras dotaciones (especial significación adquiere para determinado segmento turístico de contrastada potencialidad en los destinos maduros del litoral andaluz -jubilados europeos, principalmente- la presencia de equipamientos sanitaros y asistenciales). Con esta regulación, el Decreto vehicula aquellas reflexiones disciplinares que vinculan la competitividad de los espacios turísticos con la combinación funcional entre el alojamiento turístico reglado y las dotaciones, entendiendo que el argumento principal para la ordenación y el uso social de estas áreas son los servicios y las actividades ofrecidas al turista para el consumo del tiempo de ocio. Una implantación turística no es un barrio tradicional. Sus usuarios proyectan otras pautas de comportamiento centradas en la «recreación del ocio» (Quero, 2004: 211). Es decir, el éxito de los espacios turísticos estriba en la posibilidad de ofrecer un consumo de tiempo prolongado y atractivo a los turistas y eso, según José Miguel Iribas, pasa por la acumulación de actividades para el intercambio y por premiar la oferta de alojamiento reglada -especialmente la hotelera- cuyo usuario suele emplear una proporción importante del tiempo diario fuera de su plaza de alojamiento (Iribas, 2003: 141-153).

Además de los usos admisibles con los campos de golf, el Decreto define aquellos que deben ser considerados incompatibles (apartado 4 del artículo 4) otorgando tal condición a los usos residenciales, comerciales, industriales, terciarios y cualesquiera otros no establecidos como compatibles. Esta disposición implica un posicionamiento indubitativamente contrario a la «dimensión inmobiliario-residencial» que ha caracterizado la implantación de campos de golf en los destinos turísticos andaluces, especialmente los del litoral (Villar y Fernández, 2013: 368). En estas piezas, el campo de golf asume un rol publicitario, un reclamo que atrae un perfil de comprador de vivienda que se ha ido estandarizando en el litoral andaluz a lo largo de estos años.

La instrumentalización del golf como elemento de negocio inmobiliario ha incidido en una intensificación del residencialismo en las áreas litorales, produciendo una utilización de marcada estacionalidad y limitada productividad económica y social a medio-largo plazo. El caso de la Costa del Sol es paradigmático en este aspecto: el modelo que finalmente se ha impuesto en este espacio turístico, resultado de la simbiosis entre la acumulación de viviendas y campos de golf, se caracteriza, según el geógrafo Juan Requejo Liberal, por su absoluto desprecio de las condiciones territoriales existentes y de sus procesos naturales. Sólo ha habido dos factores del territorio que no han sido adulterados: el clima y el mar (Requejo, 2014: 110).

Definido el régimen de usos, el Capítulo II del Decreto 43/2008 se destina a regular las condiciones y requisitos para la implantación territorial de campos de golf: (a) aptitud de los terrenos (artículo 7), (b) suficiencia de los recursos hídricos (artículo 8), (c) suficiencia y funcionalidad de infraestructuras y servicios (artículo 9) y, finalmente, (d) el mantenimiento y recuperación medioambiental de los terrenos en los que se implanten campos de golf (artículo 10).

A continuación, en el Capítulo III, se aborda la regulación de las condiciones urbanísticas para la implantación y ordenación de campos de golf, que han de quedar expresamente previstas en el Plan General de Ordenación Urbanística (PGOU), el cual tomará la decisión oportuna sobre la clase de suelo en la que se haya de desarrollar la iniciativa y garantizará las condiciones reguladas en el Capítulo II para asegurar una correcta adecuación al soporte territorial. 
La opción por la implantación del campo de golf en suelo no urbanizable deberá cumplir dos condiciones: garantizar su condición aislada en el territorio y evitar la formación de nuevos núcleos de población. Caso de inclinarse por otorgar a la actuación urbanística la clasificación de suelo urbano o urbanizable, el campo de golf y los usos complementarios o compatibles asociados deberán quedar integrados en un único sector independiente y separado de los sectores residenciales o de otros usos incompatibles. Esta decisión del legislador provocó un rechazo generalizado tanto de Ayuntamientos como, especialmente, de propietarios de suelo y promotores inmobiliarios, esgrimiendo la excusa de que se estaba abocando a la inviabilidad económica la promoción de campos de golf en Andalucía, la cual solamente quedaba garantizada permitiendo la inclusión del uso residencial-vacacional.

Además, la ordenación de la actuación deberá garantizar la independencia física y la autonomía funcional del campo de golf respecto de los otros usos complementarios y compatibles, así como de los suelos urbanos y urbanizables colindantes, asegurando que la actividad deportiva se ejercite en condiciones de seguridad y en un entorno natural de calidad ambiental. Esta disposición es congruente con la definición que, en el artículo 4, se hacía de los «terrenos adscritos» y busca evitar a toda costa que el campo de golf se transfigure en una suerte de espacio libre privado de las actividades de alojamiento y dotacionales que pudieran contemplarse. El criterio principal de la ordenación del equipamiento deportivo es asegurar su calidad para la práctica del golf, entendiendo que se trata de una condición básica para asegurar el atractivo turístico de estas instalaciones.

En relación con los parámetros urbanísticos a adoptar, la edificabilidad máxima destinada a las instalaciones y construcciones necesarias para la actividad deportiva del golf será de 3.000 metros cuadrados -sobre rasante- para campos de 9 hoyos, 5.000 para los de 18 hoyos y 1.000 metros cuadrados más por cada 9 hoyos adicionales. Por su parte, la edificabilidad de los usos complementarios y compatibles será la establecida por el PGOU, con la condición de que si la actuación contempla el uso hotelero, éste deberá garantizar una oferta mínima de 50 habitaciones en campos de 9 hoyos y 100 habitaciones en campos de 18 o más hoyos, con una categoría mínima de 4 estrellas.

La traslación a la formulación del PGOU de la decisión final sobre qué usos deben contemplarse y cuánto de cada uno de ellos puede materializarse, parece razonable. El PGOU, responsable de la ordenación integral del territorio municipal, es el instrumento idóneo para ejercitar estas funciones decisorias con racionalidad, coherencia territorial y sensibilidad medioambiental. Ahora bien, al no establecerse en el Decreto condición alguna sobre la diversidad de usos a implantar (proporción mínima de la edificabilidad a consumir por cada categoría de usos complementarios, concreción de determinados usos pormenorizados -como los vinculados al ocio y el esparcimiento- o el establecimiento de unos estándares mínimos a cumplimentar para garantizar la complementariedad del campo de golf con otras dotaciones y equipamientos), existe el peligro de "vaciar de actividad» la iniciativa ya que, conociendo la dinámica del sector promotor-inmobiliario, no resultaría extraño que centrase todos sus esfuerzos en extraer el mayor rendimiento posible del alojamiento hotelero obviando, fundamentalmente, el capítulo de la compatibilidad dotacional, sector cuya competitividad en el mercado inmobiliario transmite grandes incertidumbres acerca de su capacidad para generar beneficios a corto plazo. 


\subsection{La irrupción de la figura del «campo de golf de interés turístico»: ¿excelencia turística o reclamo inmobiliario?}

Una vez explicitado el régimen general que regula la implantación de campos de golf en la Comunidad Autónoma, en el que se cercena de raíz el vaso comunicante entre campo de golf y segunda vivienda vacacional, el Decreto 43/2008 se aplica con denuedo en desdecirse de este posicionamiento y, de manera -al menos, aparentemente- arbitraria define una categoría especial, a la que dota de relevancia y singularidad, denominada "campo de golf de interés turístico». En su artículo 4.5, traslada a los Planes de Ordenación del Territorio de ámbito subregional (POTS) la capacidad de prever campos de golf de interés turístico en los que se autoricen otros usos complementarios o compatibles como residenciales, educativos, comerciales, industriales, terciarios o equipamientos, en los términos previstos en el Capítulo $V$.

Con esta disposición, que cabría adjetivar de sorpresiva, se inhiben todos los esfuerzos realizados por cualificar la oferta turística vinculada a los campos de golf que se han expuesto en los párrafos anteriores. La condición singular atribuible a los campos de golf de interés turístico se expresa en la admisibilidad de aquellos usos que, para las ofertas genéricas o comunes, han sido categorizados como incompatibles, con especial énfasis en los usos residenciales. No se alcanza a entender este cambio de rumbo tan radical. La especial relevancia de estas iniciativas estratégicas se fundamenta en fomentar el desarrollo de ofertas inmobiliario-residenciales asociadas a la instalación deportiva, precisamente el producto urbanístico del que, al parecer, había que desprenderse para fortalecer la competitividad de un sector económico con un peso específico trascendental para la Comunidad Autónoma de Andalucía y evitar la degradación sostenida e irrefrenable que han experimentado territorios de máxima sensibilidad medioambiental, como el dominio territorial del litoral .

Ante este viraje regulatorio tan sorprendente, no cabe otra interpretación que admitir la claudicación de la Administración Autonómica a la presión ejercida por los ayuntamientos y el sector de propietarios de suelo y promotores inmobiliarios por evitar la paralización de la «máquina de crecimiento» (Roch, 2001: 6) en que se convirtieron los territorios más dinámicos de la región andaluza en la década 1997-2007. En ese periodo, la mayor parte de los gobiernos locales manifestaron su disposición activa hacia el crecimiento urbano, transformándose en una suerte de «empresarios» (López y Rodríguez, 2010: 341-347) proclives a flexibilizar la regulación en materia de ordenación del territorio y urbanismo para poder vehicular sin trabas las iniciativas del sector privado, que suelen estar valoradas como inherentemente buenas para la economía, el futuro, la modernidad y, especialmente, el empleo.

Y, además, para instrumentar esta suerte de sinrazón territorial se habilita a la planificación subregional a que pueda prever este tipo de iniciativas, ampliando su capacidad para "desordenar el territorio» que ya estaba empezando a ser ensayada -con el objetivo de superar los límites al crecimiento urbano impuestos por la Norma 45 del Plan de Ordenación del Territorio de Andalucía (POTA)- mediante la delimitación de las denominadas «áreas de oportunidad supramunicipal» que, por su condición estratégica, quedan excluidas del cómputo (Zoido, 2010) .

Vista la nueva orientación funcional asignada a esta categoría especial, que recupera la recurrente simbiosis entre campo de golf y el uso residencial-vacacional, más que campos de golf de interés turístico habría que denominarlos de «interés inmobiliario». 
Los campos de golf de interés turístico quedan definidos en el artículo 22 del Decreto como aquellas instalaciones que, reuniendo las características definitorias contenidas en el artículo 2 del presente Decreto, tengan una especial relevancia por su incidencia potencial en la cualificación de la oferta turística y su desestacionalización, ampliando la oferta deportiva y de ocio asociada al turismo del ámbito territorial donde sean implantados.

La propia definición lleva inoculado el «virus de la incongruencia», toda vez que, como se ha comentado anteriormente, la inmensa mayoría de las reflexiones disciplinares fundamentan la grave estacionalidad que sufre el territorio turístico en, precisamente, el protagonismo ejercido por el alojamiento residencial frente a fórmulas de establecimientos de alojamiento reglado. Es decir, el Decreto 43/2008 pretende vincular la apuesta por la desestacionalización del turismo -el gran caballo de batalla de la ordenación de los espacios turísticos- con el uso que menos contribuye a ello -la segunda residencia (Vera, 2005: 112)- y lo incorpora como aportación funcional básica para garantizar la especial significación que se asigna a los campos de golf de interés turístico.

En todo caso, el uso global asignable a estas actuaciones debe ser el «turístico» en los términos regulados en la Disposición Adicional Novena de la LOUA, según la cual gozan de dicha calificación aquellos suelos en los que un porcentaje superior al 50\% de la edificabilidad total asignada al ámbito se destine a establecimientos de alojamiento turístico, pudiendo optar entre el abanico de tipologías contemplado en la legislación sectorial. No obstante, este porcentaje puede reducirse en 5 puntos porcentuales siempre que la edificabilidad correspondiente a este último porcentaje se destine a cualesquiera otros servicios turísticos definidos como tales en la legislación turística.

Por consiguiente, la edificabilidad destinada a alojamientos en los campos de golf de interés turístico deberá concretarse, en una importante proporción, en establecimientos de alojamientos turísticos que consumirán, como mínimo, el $46 \%$ de la edificabilidad total asignada al ámbito. Es importante destacar que, dentro de las fórmulas de alojamiento admitidas -frente a lo regulado en el régimen general de usos complementarios de los campos de golf- se encuentra el «apartamento turístico», tipología que presenta una carga de negatividad -en la percepción del sector inmobiliario como producto comercializable- considerablemente inferior al de los establecimientos hoteleros, toda vez que, a la postre, se trata de un «edificio residencial gestionado como un hotel».

No obstante, pese a la teórica prevalencia del alojamiento turístico, la realidad es que la presencia del uso residencial va a ser determinante (como máximo el $49 \%$ de la edificabilidad total) e incluso, si se aplica el descenso porcentual admitido en la Disposición Adicional Novena de la LOUA, puede convertirse en la forma de alojamiento mayoritaria (49\% para usos residenciales, $46 \%$ para alojamientos turísticos y $5 \%$ para otros servicios turísticos).

Como se ha comentado anteriormente, la legitimación para promover la implantación de campos de golf de interés turístico está conferida a los POT de ámbito subregional. Sin embargo, atendiendo tanto a la inexistencia de POTS en algunas unidades territoriales subregionales, como a la posible ausencia de reconocimiento expreso de la iniciativa declarada de interés turístico en la planificación subregional vigente, el Decreto regula el procedimiento a seguir en ambos supuestos, desvelándose la sumisión de la planificación territorial a las exigencias del mercado inmobiliario.

Así, en el supuesto de que el POT de ámbito subregional en vigor no contuviera determinaciones sobre la implantación de campos de golf de interés turístico o, caso de contenerlas, fuesen distintas a las establecidas en la declaración, el Decreto obliga a incorporar las nuevas determinaciones 
que resulten necesarias para reconocer la iniciativa declarada de interés turístico, mediante el oportuno procedimiento, de modificación o revisión, en función del alcance de la actuación. Por otra parte, en el caso de que, en el emplazamiento previsto por la iniciativa sobre la que ha recaído la declaración de interés turístico, no exista POT de ámbito subregional, en el acto de la declaración se instará a la Consejería competente en materia de ordenación del territorio a la formulación del mismo, concretando el ámbito al que debe referirse dicho instrumento.

En conclusión, el otorgamiento de la declaración de interés turístico a una iniciativa de campo de golf obliga a modificar las determinaciones del POT en vigor al objeto de contemplarla o, caso de no existir, a formular ex novo el POT del ámbito subregional en el que se pretenda implantar. La prevalencia de la «declaración sobre la planificación»-o, expresado de manera similar, de la iniciativa privada sobre el interés general- es evidente. La hoja de ruta para la implantación de un campo de golf de interés turístico no comienza con su previsión en el instrumento competente para ordenar el territorio, sino que se inicia en la concepción autónoma e individualizada de la iniciativa que se vehiculará - una vez sea declarada de interés turístico- hacia el POT de ámbito subregional, aun cuando ello suponga un cambio radical en el modelo territorial propuesto -en el caso de POT existente- o la predefinición del que haya que prever en la formulación de un nuevo POT.

La anunciada capitulación de la planificación territorial se manifiesta, también, en el establecimiento de los usos complementarios y compatibles que acompañan a la instalación deportiva. La concreción, por parte del plan subregional, tanto de estos usos pormenorizados como de los parámetros aplicables a cada uno de ellos (edificabilidad, densidad, caracterización tipológica o distancia mínima a la zona deportiva, para los usos residenciales), regulados en el artículo 27.1, hay que entenderla como simple traslación de las determinaciones incluidas en la propia declaración (artículo 23.2).

Es decir, la declaración propone dónde se implanta el campo de golf de interés turístico, cuanto suelo consume, define su ordenación detallada y los usos pormenorizados a contemplar con sus respectivas intensidades (densidad y edificabilidad residencial, entre otras), mientras que la planificación subregional, al encontrase obligada a contemplar esta iniciativa, define cómo se ha de producir dicha integración (accesibilidad, movilidad y transporte, refuerzos de la dotación infraestructural que sean precisos, impacto en el sistema de espacios libres, equipamientos supramunicipales necesarios, corrección de impactos causados en el paisaje, posible levantamiento de protecciones cautelares para habilitar la implantación, etc) en la estructura territorial la cual, caso de existir POT, es previsible que vaya a sufrir una importante transformación causada por el notable impacto provocado por el «aterrizaje imprevisto» de actuaciones de este rango y, en el supuesto de que no exista, va a nacer hipotecada por la obligación de contemplar la iniciativa prevista en la declaración.

Otra cuestión de importancia trascendental a destacar en el diagnóstico del marco regulatorio definido en el Decreto 43/2008, tiene que ver con el impacto que la implantación de campos de golf de interés turístico va a ocasionar en los modelos urbano-territoriales existentes. En este sentido, el artículo 23.5 dispone que toda actuación contemplará junto al campo de golfy, en su caso, junto al residencial, las dotaciones exigidas en el artículo 17.1 de la Ley 7/2002, de 17 de diciembre, e incluirá los usos complementarios y compatibles necesarios, tanto en tipología como en cantidad para conformar un núcleo independiente, autónomo, ordenado y completo como nuevo núcleo urbano. 
Esta regulación impone, como única alternativa de ordenación territorial, la configuración de nuevos núcleos de población asociados a la implantación de campos de golf de interés turístico, inhabilitando planteamientos que promuevan localizaciones en continuidad con estructuras urbanas existentes, circunstancia que resulta sorprendente, porque parece caminar a la contra de las determinaciones, criterios y objetivos de ordenación regulados tanto en la LOUA, como en el POTA.

Efectivamente, la LOUA regula, en su artículo 9, el objeto de los Planes Generales de Ordenación Urbanística y determina que, en el marco de los criterios y fines de la actividad urbanística explicitados en el artículo 3 y, en su caso, de las determinaciones de la planificación territorial, se deberá optar por el modelo de ordenación y las soluciones que mejor aseguren, entre otras cuestiones, los crecimientos en continuidad con las estructuras urbanas consolidadas. La LOUA apuesta por crecimientos urbanos comedidos, primando su correcta articulación con la ciudad existente frente a la dispersión territorial que, incluso, es adjetivada expresamente de «innecesaria» en el propio texto legislativo. De ahí que solamente en supuestos excepcionales sustentados en motivaciones objetivas, deban permitirse desarrollos urbanísticos (industriales, turísticos, de segunda residencia, u otros) desvinculados de los núcleos de población.

El devenir de estos años de explosión territorial ha puesto de manifiesto el error de esta excepción a la regla general, en especial en lo referente a la segunda residencia, toda vez que la admisión de nuevos núcleos de población destinados a residentes vacacionales promueve la conformación de "ciudades fantasma» que transitan del pleno rendimiento durante los periodos vacacionales, a la más absoluta inactividad el resto del año. Ejemplos no faltan en la geografía andaluza, algunos de ellos, resultado de iniciativas lideradas por la propia Administración Autonómica (el caso de Costa Ballena, a caballo entre los municipios de Rota y Chipiona, es sintomático de esta situación).

Por su parte, el conjunto de criterios y objetivos de ordenación territorial explicitados en el POTA (Jordano, 2009), configura una estrategia global de intervención para el territorio andaluz y, específicamente, para el dominio territorial del litoral, que no parece casar adecuadamente con lo regulado en el Decreto 43/2008 toda vez que, entre los principios en los que se hace descansar, destaca la defensa de un sistema y modelo de ciudad, en su conjunto, acorde con la tradición mediterránea, compacta, funcional y económicamente diversificada, estableciendo la obligación inexcusable de evitar los procesos de expansión indiscriminada y de consumo innecesario de recursos naturales y suelo, favoreciendo la creación de proximidad funcional, atributo urbano imprescindible para garantizar la implementación de medidas orientadas a proporcionar una movilidad sostenible.

La excepcionalidad inherente a los campos de golf de interés turístico debe anudarse, indefectiblemente, a la instrumentación de estrategias de ordenación territorial de ámbito subregional que, atendiendo a los valores a proteger en el territorio objeto de ordenación, a las potencialidades turísticas a desarrollar, a la caracterización del sistema de asentamientos, a la accesibilidad territorial multimodal existente y/o prevista o a la red de centralidades a diseñar al objeto de reequilibrar la unidad territorial, pudiesen determinar la conveniencia de promover la conformación de un nuevo núcleo de población motivado en la relevancia territorial aportada por un campo de golf de interés turístico. Difícilmente esta condición relevante puede ser otorgada desde propuestas individualizadas -y descoordinadas- concebidas con una visión puramente empresarial-inmobiliaria. Su contribución a la desfiguración del sistema de asentamientos del ámbito 
territorial objeto de la implantación es más que previsible, ampliando exponencialmente la capacidad, antes reseñada, conferida a la planificación subregional para «desordenar del territorio» (Górgolas, 2017). En este caso, además, con el agravante -en relación con las áreas de oportunidad supramunicipal- de resultar una iniciativa impuesta al POT, que se encuentra obligado a su reconocimiento adaptando, para ello, sus determinaciones -por el procedimiento que se indique en la resolución del Consejo de Gobierno- a los proyectos de campos de golf que hayan sido declarados de interés turístico.

No obstante, pese al ataque perpetrado a la planificación territorial -como instrumento expresivo de una determinada estrategia política- que se destila de las reflexiones expuestas, el único aspecto que aporta cierta sensatez a la regulación diagnosticada, es que la implantación de estas iniciativas no puede soslayar su previsión expresa en el POT de ámbito subregional. Ello significa que su desarrollo urbanístico se anuda a que el instrumento de planificación territorial se encuentre aprobado definitivamente y en plena vigencia sus determinaciones y que, además, la actuación haya sido incorporada al PGOU respectivo, optando por la alternativa que mejor asegure su integración en la ordenación estructural (artículo 27.3).

Es decir, la declaración de interés turístico establece las condiciones a cumplir por la implantación territorial de la iniciativa, la caracterización de los usos pormenorizados propuestos y la definición de sus parámetros urbanísticos, pero no tiene potestad para ejercer el control de su programación temporal, la cual depende de la entrada en vigor del plan subregional en cuyo ámbito se implante y de su integración en el PGOU del municipio correspondiente a su localización. Esta circunstancia fue mal recibida por los promotores inmobiliarios y los ayuntamientos afectados que entendieron la imposición de previsión en el POT de ámbito subregional -condición ineludible para la habilitación de estas iniciativas territoriales- como una postergación inasumible de las mismas.

Finalmente, el Decreto trata de maquillar esta indiciaria sumisión a los requerimientos de la iniciativa privada -deducida de las cuestiones expuestas en los párrafos precedentes- incorporando -artículos 24 y 25 - un conjunto de prescripciones técnicas suplementarias impuestas a la instalación deportiva de estas iniciativas singulares (superficie mínima, régimen de distancias de las edificaciones a la zona de juego, requerimiento infraestructurales, exigencia de obtención de certificados de calidad, etc) y acciones para la sostenibilidad (mejoras paisajísticas, sistemas de gestión ambiental, eficiencia energética, medidas de responsabilidad social corporativa) que sólo cabe interpretar como «señuelos semánticos» que desvían la atención del ataque ejercido al sistema legalmente diseñado para que la administración pública ejerza sus competencias plenas en materia de ordenación del territorio y urbanismo.

Por último, reseñar algunos apuntes de gran interés sobre la tramitación de los procedimientos de declaración de campos de golf de interés turístico, establecida en el artículo 28 del Decreto 43/2008. En primer lugar, destaca el diseño de un procedimiento muy reducido, que establece un plazo máximo de seis meses desde la presentación del proyecto (por persona promotora) ante el órgano competente y su aprobación por parte del Consejo de Gobierno. Durante este procedimiento, las iniciativas precisan recabar un informe de incidencia territorial, así como obtener la autorización exigible, de conformidad con los procedimientos de prevención y control ambiental establecidos en la legislación vigente. La preferencia por esta suerte de «tramitación-exprés» se fundamenta en que, una vez concluido el procedimiento de la declaración, hay que iniciar la modificación, revisión o formulación ex novo del POT del ámbito subregional en el que se implante 
la iniciativa. Es decir, para su materialización, al plazo establecido en el citado artículo 28 hay que acumular el preciso para aprobar definitivamente la innovación o nueva formulación del instrumento de planificación territorial, que se prevé prolongado.

Pero, sin duda, el aspecto de mayor calado, en materia procedimental, regulado en el Decreto es que la iniciativa se entiende estimada si, vencido el plazo estipulado de seis meses, no hubiere recaído acuerdo expreso. Como se verá a continuación, esta decisión ha causado un importante enfrentamiento entre la Administración Autonómica y los promotores de estas iniciativas, que ha devenido la judicialización de un importante número de procedimientos aprobados por silencio administrativo.

\section{La Ley $1 / 2008$ y el Decreto 309/2010, de 15 de junio, por el que se modifica el Decreto 43/2008}

Apenas unos meses después de la aprobación del Decreto 43/2008, la formulación de la Ley 1/2008, de 27 de Noviembre, de medidas tributarias y financieras de impulso a la actividad económica de Andalucía y de agilización de los procedimientos administrativos, introduce una Disposición Final Segunda, por la que se modifica la Ley 1/1994, de 11 de enero, de Ordenación del Territorio de Andalucía (LOTA), al objeto de agilizar las iniciativas de implantación de los campos de golf que sean declarados de interés turístico.

Esta Disposición Final Segunda incorpora un nuevo Título V en la LOTA denominado «De las declaraciones de campos de golf de interés turístico» en el que se regula (artículo 40) la innecesaridad de incluir este tipo de iniciativas en el plan subregional para admitir su implantación bastando, para ello, la aprobación de la declaración por el Consejo de Gobierno. Al tiempo, las determinaciones incorporadas en ésta vincularán al planeamiento urbanístico afectado, que queda obligado a integrarlas en su modelo territorial a través de la preceptiva innovación de aquel. Por último, se añade un párrafo final al apartado 2 del artículo 38 de la LOTA en el que se regula que la declaración por el Consejo de Gobierno de actuaciones de interés autonómico cuyas determinaciones supongan una alteración de los Planes de Ordenación del Territorio de ámbito subregional implica la modificación de dichos planes.

Recordemos que el apartado 4 del artículo 1 del Decreto 43/2008 otorgaba a los campos de golf que se implanten en Andalucía la condición de actuaciones de «incidencia territorial e interés supramunicipal», a los efectos previstos en la legislación en materia de ordenación del territorio y urbanismo. Pues bien, las iniciativas de campos de golf sobre las que recaiga la declaración de interés turístico se consideran, además, actuaciones de «interés autonómico» y a partir de la Ley $1 / 2008$, las determinaciones incorporadas en el proyecto para el que se solicita tal declaración comportan - una vez aprobada ésta por el Consejo de Gobierno- la modificación de aquellas disposiciones del POT de ámbito subregional que se estuviesen alterando con dicha aprobación. Es decir, a partir de la Ley 1/2008, la declaración de una iniciativa de campo de golf de interés turístico no necesita ser reconocida - por la vía de su modificación o revisión en función del alcance de las alteraciones propuestas- por el plan subregional afectado por la implantación.

Esta medida, indudablemente, agiliza el procedimiento de aprobación de estas iniciativas, si bien a costa de promover la «desregulación», de deslegitimar la función pública consustancial a la ordenación del territorio. La modificación propuesta en la LOTA supone «obviar la escala subregional de la planificación territorial» lo que, a la postre, implica diseñar una auténtica estrategia 
de adulteración del sistema de planificación pública imperante en la Comunidad Autónoma. Si grave era la imposición de la declaración de interés turístico a los POTS -regulada en el Decreto $43 / 2008$-, el otorgamiento a ésta de las funciones propias de la planificación territorial supone un atentado en toda regla al régimen de garantías que, para la propia ciudadanía, implica la formulación de un instrumento de planificación de esta escala territorial y nivel de resolución.

En conclusión, a partir de la aprobación de la Ley 1/2008, la declaración de un campo de golf de interés turístico no es que se imponga a la planificación territorial -obligándole a adaptarse a sus determinaciones- sino que se transfigura en ella. Ya no hay que modificar el POT para reconocer la actuación, porque la propia declaración de interés turístico lo está haciendo una vez recaiga sobre ella la aprobación del Consejo de Gobierno.

Pero este ejercicio de transfiguración, de usurpación de funciones, va más allá. Recordemos que, ante la ausencia de planificación subregional, el Decreto 43/2008 regulaba la necesidad de formular ex novo el POT de la unidad territorial afectada en cuyo modelo de ordenación tendría que integrarse la iniciativa declarada de interés turístico. Esto, como ya he comentado, podía suponer, en la práctica, la postergación sine die del desarrollo de la iniciativa y, por tanto, atendiendo a las demandas del sector inmobiliario, era imprescindible -y urgente- modificar taxativamente esta regulación y flexibilizarla hasta hacerla desaparecer por innecesaria.

A ello se aplica la Ley 1/2008 mediante la inclusión del citado Título V en la LOTA (artículo 40) en el que se sustituye la necesidad de formular un POT que sirva de marco justificativo a la iniciativa declarada de interés turístico, por un procedimiento de aprobación que amplía notablemente los plazos de audiencia a los municipios afectados (de 10 días a, como mínimo, dos meses), obliga a una información pública por el plazo mínimo de un mes e impone la necesidad de recabar informes, dictámenes u otros pronunciamientos de los organismos y entidades administrativas gestores de los intereses públicos afectados, además del informe de incidencia territorial y el procedimiento de Evaluación Ambiental que corresponda en función de la legislación ambiental de aplicación, que ya eran exigidos en el Decreto 43/2008. El nuevo procedimiento arbitrado es prácticamente idéntico al regulado para los instrumentos de planificación urbanística que afectan a la ordenación estructural de un término municipal.

La Ley 1/2008, en definitiva, considera innecesaria la existencia del marco de ordenación otorgado por un POT, entendiendo que bastan para ejercer tal función las determinaciones y requerimientos técnicos y medioambientales incluidos en los proyectos de iniciativas de implantación de campos de golf que hayan sido declaradas de interés turístico. La decisión que toma la Ley 1/2008 es sustituir la formulación o modificación del POT por un procedimiento de aprobación de las iniciativas de interés turístico más garantista -en materia de plazos y participación ciudadana por la vía de la información pública- y fiscalizador de los intereses púbicos que pudieran verse afectados.

Pasado un cierto tiempo, se formula el Decreto 309/2010, de 15 de Junio que tiene como finalidad modificar el Decreto 43/2008 al objeto de adecuarlo a la regulación establecida en la Disposición Final Segunda de la Ley 1/2008. Los preceptos de nueva incorporación a destacar, inciden en tres cuestiones básicas: (a) pese a la, más que cuestionable, suplantación de la planificación territorial por la declaración de interés turístico, se mantiene la obligación de integrar la iniciativa en el planeamiento urbanístico a través de la oportuna innovación, sin reparar en la significativa alteración de determinaciones sustantivas de la ordenación estructural que, sin duda, va a ocasionar; (b) se legitima la exclusión de estas iniciativas del cómputo del crecimiento urbano a efectos de 
verificar el cumplimiento de la Norma 45 del POTA y (c) se otorga a la declaración de interés turístico, el control de los tiempos para el desarrollo de estas iniciativas. Profundicemos en estas cuestiones.

El artículo 23 del Decreto original se reforma incorporando un apartado 2 donde se certifica la innecesariedad de la planificación subregional una vez haya recaído la declaración de interés turístico sobre una iniciativa de implantación de campo de golf, la cual también asume la responsabilidad de determinar los usos complementarios y compatibles. La planificación territorial, con esta disposición, queda deslegitimada, dilapidada y orillada a la práctica insignificancia. Sin embargo, se mantiene la obligación de integrar la iniciativa en el PGOU correspondiente. Así, una vez producida la declaración, se requerirá la correspondiente innovación de los instrumentos de planeamiento urbanistico.

Esta integración difícilmente va a ser pacífica y, para significar el impacto a causar por estas iniciativas en los modelos urbano-territoriales contemplados en la planificación urbanística, convendría introducir en la reflexión la problemática asociada a la reserva obligatoria de vivienda protegida regulada en el artículo 10.1.A) b) de la LOUA para las actuaciones que contengan usos residenciales. Esta disposición legal permite eximir de esta reserva aquellos sectores o áreas de uso característico residencial que tengan una densidad inferior a 15 viviendas/hectárea y cuya caracterización tipológica no se considere apta para la construcción de este tipo de viviendas. Esta exención no significa renunciar a la reserva no satisfecha que, en todo caso, debe ser compensada mediante «su integración en el resto del municipio».

Es incuestionable que la totalidad de las actuaciones de campos de golf de interés turístico se van a encontrar en esta situación, por lo que las innovaciones preceptivas de los PGOUS no pueden restringirse a su reconocimiento e integración en el modelo urbano-territorial sino que, además, tienen que alterar el contenido urbanístico de otras actuaciones -pertenecientes a la misma clase de suelo a la otorgada a la iniciativa; es decir, al suelo urbanizable sectorizado- con la finalidad de incrementar la reserva de vivienda protegida que tuviesen asignada, para compensar la eliminada del campo de golf de interés turístico.

Ante la dificultad instrumental que comporta esta exigencia legal y la afectación a intereses particulares no comprometidos con la actuación urbanística cuya reserva se decide compensar, la Ley $2 / 2012$, de 30 de enero, que modifica la Ley 7/2002 de Ordenación Urbanística de Andalucía, regula la posibilidad de que, en procedimientos de revisión parcial o modificación del planeamiento general, en lugar de compensar -en otras actuaciones- la reserva de vivienda protegida eximida, se incremente la cesión de aprovechamiento correspondiente a la administración actuante, desde el 10\% estipulado en el artículo 51.1.C).e) de la LOUA, hasta un máximo del $20 \%$ a los efectos de revertir las plusvalías generadas por dicha exención. El destino principal de esta cesión de aprovechamiento, obviamente, es su monetización para ampliar el Patrimonio Público del Suelo, ya que el tipo residencial en el que se ha de materializar no forma parte de las estrategias habituales de promoción de vivienda pública.

Esta nueva determinación legal genera muchas incertidumbres, sospechas incluso, sobre el proceder de la administración local en dos cuestiones primordiales: (a) el establecimiento del porcentaje de cesión de aprovechamiento a incrementar, que puede oscilar desde el $11 \%$ al 20\%, y (b) la valoración económica de la monetización correspondiente. Dependiendo de la decisión adoptada en ambas cuestiones se puede estar premiando -o no- a la iniciativa privada promotora de estos proyectos, posibilidad que, lamentablemente, no puede resultarnos extraña analizando 
el periodo histórico del último boom inmobiliario y su íntima vinculación con los procesos de corrupción urbanística que han asolado nuestra Comunidad.

En relación con la segunda de las cuestiones antes apuntadas -la obligada observancia de las normas del POTA- el Decreto 309/2010 introduce un apartado 6 en el artículo 27 donde se ratifica la eliminación del crecimiento urbanístico computable -a efectos del cumplimiento de la Norma 45- de las iniciativas de implantación de campos de golf que hayan sido declaradas de interés turístico. Esta disposición era absolutamente necesaria, toda vez que al eliminar de escena a los POT de ámbito subregional -instrumentos empleados por la Administración Autonómica para decidir la exención del cómputo del crecimiento urbano de determinadas actuaciones estratégicas-, había que arbitrar una fórmula alternativa que procediese a excluir estas iniciativas. En este caso, la capacidad decisoria no recae, obviamente, en la propia declaración, sino en el acuerdo del Consejo de Gobierno aprobatorio de la misma, que habrá de explicitar dicha eliminación.

Finalmente, se introduce una nueva regulación (artículo 29.4) en materia de programación de la actuación declarada de interés turístico, otorgando a la declaración la potestad para determinar los plazos de la correspondiente innovación del planeamiento urbanístico, así como de la ejecución e implantación efectiva de la actuación, pudiendo ser prorrogados -a solicitud de la entidad promotora o del ayuntamiento afectado- cuando el retraso esté motivado por causas suficientemente justificadas. Como era de esperar, a tenor de las nuevas atribuciones otorgadas a la declaración de interés turístico, el Decreto 309/2010 no podía dejar de incluir entre éstas, la decisión sobre los plazos temporales a cumplimentar para su efectiva implantación y la posibilidad -como finalmente así ha ocurrido- de facilitar su incumplimiento a través de la solicitud de una prórroga suficientemente motivada.

En conclusión, la Ley 1/2008 y el Decreto 309/2010 se esmeran en anular los efectos del único precepto que -entre los regulados en el Decreto 43/2008- era percibido como un impedimento a derribar, para perfeccionar la desregulación del desarrollo de iniciativas de campos de golf de interés turístico: sorteando la previsión obligatoria de éstas en la planificación subregional, el territorio andaluz estaba abonado para permitir el afloramiento de estas iniciativas privadas que se imponen a la planificación pública esgrimiendo como único argumento el crecimiento económico. Así, entre los años 2008 y 2015, 37 proyectos han intentado obtener la declaración de interés turístico, de los que, afortunadamente, a día de hoy, sólo dos lo han conseguido.

\section{Comienza el camino de la reconsideración: Orden de $\mathbf{1 3}$ de marzo de 2012 por la que se desarrolla el procedimiento para obtener la declaración de campos de golf de interés turístico}

La Orden 2/2012 se redacta al objeto aportar claridad y racionalidad al proceso aprobatorio de actuaciones de campos de golf de interés turístico, que se estaba revelando muy confuso, dado el número de organismos y entidades públicas a los que se debían recabar informes -cuyo alcance tampoco había quedado explicitado con nitidez en los Decretos analizados anteriormente- para su pronunciamiento sobre las cuestiones relativas a los intereses públicos afectados. En este sentido, la Orden destaca, por encima de otros, un conjunto de informes a los que otorga la condición de «preceptivos y determinantes». Estos son: (a) el informe de incidencia territorial, (b) el informe de la Consejería competente en materia de Medio Ambiente, (c) el informe de la Consejería competente en materia de Deporte y, por último, (d) el informe de la Consejería competente en 
materia de Turismo. Estos cuatro informes sectoriales van a conformar el cuerpo principal de la evaluación y fiscalización de la iniciativa de implantación de campos de golf de interés turístico, por abarcar los campos prioritarios sobre los que se ha de fundamentar la resolución -aprobatoria o denegatoria- de la misma.

Entre ellos destaca, por el importante cambio de rumbo que promueve, el informe turístico en el que, además de valorar la potenciación de otros segmentos turísticos, más allá del golf, aprovechando la presencia de valores turísticos en el contexto territorial (oferta complementaria, modelo de alojamiento imperante, los activos naturales, paisajísticos o ambientales existentes que fundamentan la teoría de los "precios hedónicos», tan determinante en la competitividad de los espacios turísticos) se profundizará en los siguientes aspectos: (a) la prevalencia del uso turístico frente al resto de usos complementarios y compatibles (con especial referencia al uso residencial); (b) el protagonismo de la oferta de plazas en establecimientos de alojamiento turístico frente a plazas residenciales y (c) la apuesta por los establecimientos hoteleros de alta gama (4 o 5 estrellas), ampliando el número de plazas inicialmente regulado en el Decreto 43/2008.

Junto a este conjunto de informes de "carácter determinante, además de preceptivo» (¿es un informe determinante también vinculante?), el artículo 12.2 de la Orden establece que se requerirá informe a la Consejería competente en materia de urbanismo sobre la viabilidad urbanística de los proyectos, en aquellos supuestos en que los mismos tengan incidencia urbanística o prevean la implantación de usos residenciales. Este informe es una novedad respecto de la regulación contenida en los Decretos 43/2008 y 309/2010 y cabe considerarlo como un requisito adicional a la evaluación territorial y medioambiental, para garantizar la correcta integración de la iniciativa en la estructura general y orgánica del municipio en el que se pretende implantar. Además, el informe, tal y como está redactado el artículo, va a resultar obligatorio ya que es impensable concebir una actuación de estas características que no tenga incidencia urbanística o no prevea la materialización de usos residenciales cuya admisibilidad fundamenta, en gran medida, el surgimiento de la figura del campo de golf de interés turístico.

El nuevo carácter asignado a los principales informes y el contenido establecido para los mismos -en especial el relativo a la dimensión turística de la actuación- certifica el cambio de rumbo impulsado por la Orden 2/2012, en relación con la orientación funcional a contemplar en estas iniciativas. Este novedoso posicionamiento quedó anunciado en el apartado 2 del artículo 2 de esta Orden que reorienta el concepto de campo de golf de interés turístico definido en el Decreto 43/2008 y refrendado en el Decreto 309/2010, al establecer que este tipo de actuaciones deben quedar caracterizadas por su dimensión turística contribuyendo así a mejorar y cualificar la oferta de alojamiento reglado del ámbito de localización del proyecto, y a conformar una oferta complementaria y de ocio en la que estén presentes otros productos y segmentos diferentes al del turismo de golf.

Es decir, la especial relevancia y significación territorial de los campos de golf de interés turístico, además de en la excelencia de la instalación deportiva, se fundamenta -a partir de la entrada en vigor de esta Orden- de una forma nítida, clara y precisa en el protagonismo de los establecimientos de alojamiento turístico frente a las segundas residencias, y en la ampliación de la oferta dotacional incorporando otros equipamientos complementarios al campo de golf. La explicitación de lo que -por haber quedado regulado con cierta indeterminación en los Decretos estudiados- quedaba abierto a otras interpretaciones, coadyuvó a escenificar con claridad los nuevos criterios de la Administración Autonómica y certificó el inicio de un importante conflicto con 
el sector inmobiliario-financiero que aún no ha concluido. Así, la Administración ha activado el procedimiento de declaración de lesividad en las aprobaciones de campos de golf de interés turístico que se han producido por silencio positivo - un total de 17- ante el vencimiento de los plazos legalmente establecidos, para ello, en el artículo 28.9 del Decreto 43/2008. En este tipo de procedimientos se declara lesivo para el interés público un acto previamente dictado por la Administración, que es favorable para los interesados y que sea anulable -conforme a lo dispuesto en el artículo 48 de la Ley 39/2015, de 1 de octubre, del Procedimiento Administrativo Común de las Administraciones Públicas- para poder proceder posteriormente a su impugnación ante el orden jurisdiccional contencioso-administrativo.

A la vista de la convulsión, confusión e incertidumbre causada por la secuencia regulatoria analizada a lo largo del presente texto, el gobierno andaluz está, al parecer, dando pasos para volver a modificar el Decreto regulador de la implantación de campos de golf. Veremos en qué sentido.

\section{Conclusión: la desregulación de las iniciativas de campos de golf de interés turístico. ¿̨regreso al pasado?}

El diagnóstico realizado en el presente artículo, constata la deriva flexibilizadora y desregulatoria que ha seguido la regulación de los campos de golf en la Comunidad Autónoma de Andalucía, certificada con la irrupción estelar de la figura del «campo de golf de interés turístico» cuya "publicitada excelencia» se traduce, paradójicamente, en (a) admitir el uso residencial, declarado incompatible para el resto de iniciativas de campos de golf por su contrastada incidencia en la descualificación de la oferta turística del ámbito territorial objeto de implantación; (b) eludir la correcta integración territorial de las actuaciones urbanísticas vinculadas a estas ofertas deportivas singulares, adulterando la legislación autonómica vigente en materia de ordenación del territorio y urbanismo, al evitar su ideación primigenia en la planificación territorial de ámbito subregional y el planeamiento urbanístico, garantía inexcusable para obtener un modelo territorial racional y sostenible (c) promover la desnaturalización del cuerpo normativo del POTA destinado a garantizar modelos de ciudad compactos, al excluir dichas iniciativas del cómputo del crecimiento urbano a contemplar por el planeamiento general.

El objetivo de este proceder -no declarado explícitamente pero no por ello menos evidente- ha sido hacer prevalecer los intereses del sector promotor-inmobiliario frente al interés general que debe ser preservado por las administraciones públicas en el ejercicio de sus competencias en materia de ordenación territorial. Así, a pesar de las teóricas garantías procedimentales incorporadas en el texto legislativo, la hoja de ruta diseñada en éste para habilitar la implantación de campos de golf de interés turístico, sigue una dirección inversa a la coherencia territorial atribuible a los planes territoriales y urbanísticos: es la iniciativa privada la que decide el emplazamiento mientras que la administración simplemente lo autoriza, imponiendo su reconocimiento a los instrumentos de planificación pertinentes. Sorprende, además, que este proceso deslegitimador de la planificación territorial y urbanística se haya producido en plena crisis económica, una vez estallada la burbuja inmobiliaria conformada en la década del «tsunami urbanizador» (19972007).

Pero, quizás, lo más sorprendente es que, transcurrido más de medio siglo, se tenga la sensación de que nada ha cambiado desde que el 28 de diciembre de 1.963 se aprueba la Ley 197/1963 sobre Centros y Zonas de Interés Turístico Nacional, elaborada por el Ministerio de Información 
y Turismo en los años de la «efervescencia inmobiliaria» del tardofranquismo. Las similitudes entre ambos marcos regulatorios no son solamente nominales -aun siendo ciertamente sintomático este hecho- sino de contenido y alcance, especialmente en lo relativo a la prevalencia de la iniciativa privada sobre la planificación, bajo la excusa de impulsar el crecimiento económico. A la vista de las reflexiones vertidas a lo largo del texto parece que, con el paso de los años, no han variado en exceso las «obsesiones por crecer a toda costa»- en la costa, claro está- ni el desapego de la sociedad sobre el papel imprescindible que ha de ejercer la ordenación del territorio y la planificación urbana para asegurar la sostenibilidad de los modelos urbano-territoriales.

Tanto la Ley sobre Centros y Zonas de Interés Turístico Nacional como la regulación autonómica de campos de golf, diseñan un procedimiento de actuación al margen de la planificación territorial y urbanística. En el caso de la Ley 197/1963 a través de una nueva figura de planeamiento no prevista en la Legislación del Suelo vigente en aquellos años, denominada «Plan de Ordenación Territorial y Urbana» (Terán, 1999: 256), y en el caso de nuestra regulación autonómica, a través de la propia declaración de campos de golf de interés turístico que es la que determina el emplazamiento, define el régimen de usos y sus parámetros urbanísticos, e incorpora la ordenación pormenorizada de la actuación. Como vemos, la onda larga del capitalismo inmobiliario español tiene un recorrido temporal muy prolongado que abarca todo el periodo histórico que discurre entre la década de los años 60 del siglo XX hasta nuestros días (López y Rodríguez, 2010).

\section{Referencias bibliográficas}

- Babinger, Frank (2012). «El golf en España: la concentración social y territorial de un fenómeno que trasciende ampliamente lo deportivo». Ería (88), 185-197.

- Barranco, Rafael y Fernández, Antonio L (2009). «La problemática jurídica de los campos de golf (I): aspectos turísticos y deportivos. Los campos de golf de interés turístico en la normativa andaluza. Revista andaluza del derecho del deporte (6), 261-295.

- Barranco, Rafael (2010). «La problemática jurídica de los campos de golf (II): condiciones ambientales y urbanísticas. Especial referencia al Decreto andaluz de campos de golf». Revista andaluza del derecho del deporte (8), 325-370.

- Blanquer, David (2002). El golf: mitos y razones sobre el uso de los recursos naturales. Valencia: Tirant Lo Blanch.

- Blanquer, David (2005). «El golf: de la adecuada utilización del ocio, al uso racional de los recursos naturales». En: Blanquer, David (coord.).Salud, Deporte y Turismo (7º Congreso de Turismo, Universidad y Empresa). Valencia: Tirant Lo Blanch.

- España (1963). Ley 197/1963, de 28 de diciembre, sobre «Centros y Zonas de Interés Turístico Nacional». Boletín Oficial del Estado de 31 de diciembre de 1963, 313.

- García Rubio, Fernando. (2005). «Régimen jurídico-administrativo de los campos de golf». Cuadernos de Derecho Local (8), 162-175.

- Górgolas, Pedro (2017). «La planificación territorial de ámbito subregional en el litoral andaluz: de la «condescendencia» con el planeamiento general en vigor a la «adulteración» del modelo de ciudad regulado en el Plan de Ordenación del Territorio de Andalucía». Práctica urbanística (147), 1-19. Editorial Wolters Kluwer.

- Iribas, José Miguel (2003). «Evolución de las rutinas en el uso del espacio; las diferentes tipologías turísticas. En: Arquitectura moderna y turismo: 1925-1965. Actas del IV Congreso Fundación Docomomo Ibérico. Valencia: Universidad Politécnica de Valencia.

- Jordano, Jesús (2009): «Políticas Autonómicas de Medio Ambiente. XIV. Andalucía: Desarrollo sostenible y límites a los crecimientos urbanísticos». En: López Ramón, Fernando (coord.). Observatorio de Políticas Ambientales 2009. Thomson Reuters Aranzadi.

- Junta de Andalucía (2002). Ley 7/2002 de Ordenación Urbanística de Andalucía (revisión vigente desde el 6 de Agosto de 2016). http://www.juntadeandalucia.es 
- (2006). «Decreto 206/2006, de 28 de noviembre, por el que se adapta el Plan de Ordenación del Territorio de Andalucía a las Resoluciones aprobadas por el Parlamento de Andalucía». Boletín Oficial de la Junta de Andalucía, de 29 de diciembre de 2006, 250.

- (2008). Decreto 43/2008, de 12 de febrero, regulador de las condiciones de implantación y funcionamiento de campos de golf en Andalucía. Boletín Oficial de la Junta de Andalucía de 27 de febrero de 2008, 41.

- (2008) Ley 1/2008, de 27 de Noviembre, de medidas tributarias y financieras de impulso a la actividad económica de Andalucía y de agilización de los procedimientos administrativos. http://www.juntadeandalucia.es

- (2010) Decreto 309/2010, de 15 de junio, por el que se modifica el Decreto 43/2008 a las Resoluciones aprobadas por el Parlamento de Andalucía». Boletín Oficial de la Junta de Andalucía de 18 de junio de 2010, 119.

- (2012). Ley 2/2012 de 30 de enero de modificación de la Ley 7/2002 de 17 de diciembre de Ordenación Urbanística de Andalucía. http://www.juntadeandalucia.es

- (2012). Orden de 13 de marzo de 2012 por la que se desarrolla el procedimiento para obtener la declaración de campos de golf de interés turístico. Boletín Oficial de la Junta de Andalucía de 22 de marzo de 2012, 57.

- López, Isidro y Rodríguez, Emmanuel (2010) Fin de Ciclo. Financiarización, territorio y sociedad en la onda larga del capitalismo hispano (1959-2010).Madrid: Traficantes de Sueños.

- Mellado, Lorenzo (2009). «Los campos de golf de interés turístico en Andalucía. Notas sobre su régimen jurídicoadministrativo». Revista Andaluza de Derecho del turismo (2), 11-48.

- Navarro, Enrique (2008). «La redefinición de un destino a partir del turismo residencial. El caso de la Costa del Sol. En: Antón, Salvador y González, Francesc (coords). A propósito del turismo. La construcción social del espacio turístico. Barcelona: Editorial UOC, 273-281.

- Ortega, Rodrigo J (2008), «Los campos de golf y su régimen jurídico autonómico comparado. La nueva normativa andaluza en la materia: el Decreto 43/2008, de 12 de febrero». El Consultor de los Ayuntamientos y de los Juzgados, 20, Tomo 3.

- Ortega, Rodrigo J (2010). «La «guerra del oro verde» o la normativa andaluza de 2008 en materia de campos de golf (desde una perspectiva urbanístico-territorial)». CEFLegal: revista práctica de derecho. Comentarios y casos prácticos (114), 119.

- Paniza, José L (2005a). La percepción social del golf. Sevilla: Consejería de Turismo, Comercio y Deporte.

- Paniza, José L (2005b). «El golf como fenómeno deportivo turístico». En: Blanquer, David (coord.). Salud, Deporte y Turismo. Valencia: Tirant Lo Blanch.

- Quero, Damián (2004). «La urbanización del turismo. Un punto de vista clásico». En: Aurioles, Joaquín (Coord). Las nuevas formas del Turismo. Almería: Mediterráneo Económico. Instituto Cajamar, 197-214.

- Requejo, Juan (2014). «El regreso a los orígenes de la Costa del Sol. Contexto territorial, ambiental y social del turismo», En: Escuredo, Rafael y Cano, Juan (Eds.).Urbanismo y vivienda en Andalucía. Almería: Universidad de Almería. Cátedra Rafael Escuredo, 101-116.

- Roch, Fernando (2001). «Hegemonía inmobiliaria y desregulación urbanística. El declive del Plan creador». Urban (6), 6-14.

- Terán, Fernando (1999). Historia del urbanismo en España III. Siglos XIX y XX. Ediciones Cátedra, Madrid.

- Vera, José Fernando (2005). «El auge de la función residencial en destinos turísticos del litoral mediterráneo: entre el crecimiento y la renovación». Papers (37-38), 95-114.

- Villar, Arsenio (2008). «Los espacios de golf en el litoral de Andalucía: Patrones espaciales y evolución en el período 1998-2004». Ería (76), 247-266.

- Villar, Arsenio (2010). «Territorio, Turismo y Paisaje. El proceso de urbanización en el Litoral de Andalucía. El papel de los Campos de Golf». Tesis Doctoral. Sevilla: Departamento de Geografía Física y Desarrollo Geográfico Regional de la Universidad de Sevilla.

- Villar, Arsenio y Fernández, Alfonso (2013). «Diagnóstico y perspectiva territorial del golf en Andalucía: entre la cualificación turística y el desarrollismo inmobiliario». Boletín de la Asociación de Geógrafos Españoles (62), 357-378.

- Zoido, Florencio (2010). «Ordenación del Territorio en Andalucía. Reflexión personal». Cuadernos Geográficos No 47: 189-221. 


\section{Sobre el autor}

Pedro Górgolas Martín

Arquitecto por la ETSA de Sevilla, especialidad de Urbanismo (Junio de 1988). Máster en Proyectos Arquitectónicos. Fundación Antonio Camuñas, Centro Superior de Arquitectura (1992). Doctor por la Universidad de Sevilla (Enero de 2017).

Profesor del Departamento de Urbanística y Ordenación del Territorio de la Universidad de Sevilla desde noviembre de 1988 hasta la actualidad. Profesor en diversos Máster universitarios (Universidad de Sevilla y Universidad de Granada) y de instituciones privadas (Fundación Cajasol, Colegio de Arquitectos de Sevilla, Instituto de Práctica Empresarial). Director de cursos de formación impartidos en la fundación FIDAS del Colegio de Arquitectos de Sevilla.

Desde 1998, en el seno de la consultora Territorio y Ciudad SLP, he participado, formando parte del equipo de dirección, en la redacción de instrumentos de planificación territorial y planeamiento urbanístico. 